\title{
Retrospective Analysis of Biological and Technical Complications Using Individual CAD/CAM Abutments
}

\author{
Ali-Reza Ketabi ${ }^{1 *}$, Sandra Ketabi ${ }^{1}$, Martin Brenner ${ }^{1}$, Hans-Christoph Lauer ${ }^{2}$ and Silvia Brandt ${ }^{2}$ \\ ${ }^{1}$ Medical Dentistry, Private Practice, Epplestr. 29a, Stuttgart, Germany \\ ${ }^{2}$ Department of Prosthodontics, University Frankfurt am Main, Frankfurt am Main, Germany
}

"Corresponding author: Dr. Ali-Reza Ketabi, Doctor of Medical Dentistry, Private Practice, Epplestrasse 29A, Stuttgart, Germany, Tel: +49 $711-4400952 ;$ Fax: +49 711 - 633969 78; E-mail: alirezaketabi@yahoo.de

Received date: August 07, 2017; Accepted date: August 24, 2017; Published date: August 31, 2017

Copyright: (c) 2017 Ketabi AR, et al. This is an open-access article distributed under the terms of the Creative Commons Attribution License, which permits unrestricted use, distribution, and reproduction in any medium, provided the original author and source are credited.

\begin{abstract}
Purpose: The aim of the present study was to assess the biological and technical complication and survival rates of implants and prosthetic superstructures using custom-milled CAD/CAM abutments made of titanium or zirconia.

Material and Methods: A total of 109 patients were treated with 225 AstraTech OsseoSpeed implants (Dentsply $\mathrm{IH}$ ) between July 2008 and November 2012 in the same private dental practice. Following submerged healing, the implants were uncovered and restored with Atlantis custom CAD/CAM abutments made of zirconia or titanium. Single crowns, fixed bridges, or telescope crowns as attachments for removable prostheses were connected to the abutments with zinc oxide phosphate cement. Patients were clinically and radiologically followed at the abutment level for a mean 20.85 months. The clinical assessment included biological and technical complications a well as the survival of the implants, abutments, and prosthetic superstructures. Mean crestal bone loss was assessed on standardized radiographs. Patient satisfaction was surveyed with a self-developed questionnaire.
\end{abstract}

Results: The records of 69 patients (49 female, 20 male: mean age: 53.51 years) treated with 124 implants/ custom abutments were included in the final analysis. Most abutments were made of titanium ( $n=90)$, followed by zirconia $(n=34)$. The survival rates of implants and abutments were $100.00 \%$. Eight restorations $(6.50 \%)$ had to be replaced during follow-up, for an implant/abutment-related cumulative prosthetic success rate of $93.50 \%$. The patient-related cumulative prosthetic survival rate was $92.75 \%$. A mean bone gain of $0.06 \mathrm{~mm}$ (SD: $0.28 \mathrm{~mm}$ ) on the mesial side and $0.11 \mathrm{~mm}$ (SD: $0.37 \mathrm{~mm})$ at the distal side of the implants $(n=122)$ was recorded. Only a few cases of soft-tissue complications such as mucositis, loss of papilla height, or bleeding on probing were observed. Therapy was rated as very good by $92.65 \%$ of patients. The esthetic result was assessed as very good as well by the majority of patients (88.41\%). Due to the small sample size, no tests for statistical significance could be performed for any of the examination parameters, except for radiological crestal bone loss. No statistical significance was found for crestal bone loss as a function of the abutment material $(p \geq 0.05)$.

Conclusions: Individual CAD/CAM -abutments are a good and predictable treatment option and deliver high patient satisfaction concerning the therapeutic and esthetic results.

Keywords Custom abutments; Emergence profile; CAD/CAM; Softtissue management; Implant prosthetics

\section{Introduction}

Abutments are important as links between implants and the prosthetic superstructure. They are also a very important determinant for biological, technical, and esthetic parameters. Improving the connection between implant and abutment to reduce and prevent micromovements at the implant-abutment interface should therefore be a top priority in oral implantology [1]. The stability of peri-implant hard- and soft-tissue conditions is fundamental to long-term implant success and crucial for peri-implant esthetics, especially in the anterior jaw [2]. Nonetheless, remodeling of the crestal bone during the first years after implant insertion seems to be an inevitable side effect $[3,4]$.

Why bone undergoes remodeling is still unclear. Influencing parameters - such as flap vs. flapless technique [5,6], implant position, the positioning of the microgap between abutment and implant (supracrestal, epicrestal, or subcrestal) [7], or abutment diameter (platform switching/platform shifting) [8-10] - have been proposed but not yet proven. Material-specific surface properties of the implant and abutment also seem to have an influence on the healing process and the biological reaction of the peri-implant hard and soft tissues.

In an in vitro study, smooth metallic surfaces of biomaterials promote epithelial cell adhesion and cell spreading more than surfaces made of dental ceramic materials [11]. The current literature reveals no significant or clinical differences in survival rates, technical and biological complications, soft-tissue parameters, radiological bone loss, esthetic parameters, or patient-reported outcomes around abutments made of titanium or zirconia [12], However, zirconia abutments seem to deliver better esthetic results than abutments made of titanium $[12,13]$. Titanium and zirconia surfaces both promote the establishment of hemidesmosomal connections between epithelial cells and abutment surface, building a mucosal barrier similarly to the junctional epithelium around natural teeth $[14,15]$, which is one of the 
main targets of hard- and soft-tissue preservation in implant therapy [16].

There seem to be no significant differences in crestal bone resorption a function of the abutment material, whether alumina, zirconia, titanium, or gold alloys [17]. Platform-switching (or platform-shifting) is assumed to result in significant reduced bone remodeling and better preserved soft tissue than abutments with a matching standard diameter $[8,10,18-22]$.

More recent animal studies and systematic reviews have shown confusing results in that they failed to demonstrate a positive influence of reduced-diameter abutments on peri-implant tissue stability $[4,23,24]$. In addition to the biocompatibility of implant and abutment materials and the functional integrity of the implant-abutment interface, an emergence profile that mimics the natural tooth seems to have a substantial impact on the esthetic and functional epithelial cuff that forms around the implant neck. An optimal emergence profile can be achieved when the peri-implant mucosa is shaped formed very early by a provisional abutment [25-30].

Physiologically shaped formed provisional and final abutments created using computer-aided design/computer-aided manufacturing (CAD/CAM) seem to be a highly promising approach to shaping the ideal emergence profile $[26,27]$. CAD/CAM systems for the fabrication of individual abutments facilitate custom production of esthetically shaped abutments made of different materials such as pure titanium, titanium anodized with titanium nitride (Gold Hue), or zirconia [31-37].

CAD/CAM abutments are more precise than those created by conventional casting and fit more precisely than stock abutments [38]. A radiographic and scanning electron microscopic (SEM) assessment revealed no differences between custom and prefabricated titanium abutments by Dentsply IH with respect to their microscopic and radiographic fit at the implant-abutment interface [39]. Customdesigned Atlantis abutments (Dentsply $\mathrm{IH}$ ) are available for all major implant systems including the Astra Tech Implant System. There are notable benefits to the Atlantis system in addition to its low cost $[33,40]$, such as reduced overall treatment times $[33,41,42]$, and a simplified treatment protocol $[33,40]$.

A recently published systematic review reported the highest survival rates for implant-supported single crowns, followed by fixed partial dentures, over a follow up period of five years [43]. Despite the favorable survival rates over five years, technical, biological, and esthetic complications with respect to implant-supported fixed restorations seem to be relatively frequent [44]. While prosthodontic failure rates as a function of the retention mechanism used do not show any statistical difference between screw-retained and cemented restorations [45-48], both methods are associated with issues related to prosthodontic maintenance and complications [48]. The distribution of complication types seems to differ depending on the retention type: whereas screw-retained fixed prosthetic reconstructions showed a significantly higher incidence of technical complications, cemented reconstructions seemed to imply more biological problems [46-48].

With regard to the complication and survival rates of hybrid prosthetic superstructures on both natural teeth and implants, older systematic overviews reported lower survival rates for hybrid reconstructions $[49,50]$ and complained of the lack of longitudinal studies [50]. However, more recent reviews showed similar rates of technical complications with hybrid reconstructions as with strictly implant-supported fixed dentures if rigid functional connections between implants and natural teeth were used [51]. Despite similar complication rates, failure rates seem to be higher for fixed hybrid superstructures than for implant-supported single crowns or fixed partial prostheses [52]. The aim of the present study was to assess the biological and technical complication and survival rates of implants and prosthetic superstructures using custom-milled CAD/CAM abutments made of titanium or zirconia.

\section{Methods and Materials}

The present retrospective cohort study included 109 consecutive partially edentulous patients treated with 225 CAD/CAM Atlantis abutments between July 2008 and November 2012. Clinical and radiological parameters were assessed and documented by means of a self-developed questionnaire. Patient satisfaction in terms of esthetics and treatment results was assessed with a self-developed questionnaire as well. The study was approved by the competent Ethics Commission of the Medical Chamber of the German State of Baden-Württemberg (2013/04/09).

\section{Implants}

Implant treatment had been performed previously, between April 2008 and September 2012, using 225 Astra Tech OsseoSpeed implants (Dentsply $\mathrm{IH}$ ) after reflecting a full-thickness flap. Implants with lengths of 6 to $13 \mathrm{~mm}$ and diameters of 3.5 to $5 \mathrm{~mm}$ were inserted in the anterior and/or posterior part of the maxilla or mandible, followed by submerged healing for 2 to 6 months.

All implants were inserted using a conventional/late placement protocol, as suggested by the 4th ITI Consensus Conference [53]. The healing phase was extended if augmentation procedures with a bovine bone substitute (Bio-Oss; Geistlich Biomaterials) and guided bone regeneration (GBR) (Bio-Gide; Geistlich Biomaterials) had to be performed in conjunction with the insertion of the implant. After uncovering the implants, standard healing abutments provided by the manufacturer were used until the final restoration was fabricated and inserted. Clinical and radiological parameters were assessed one year after definitive delivery.

\section{Abutments}

Abutments were fabricated using the Atlantis Virtual Abutment Design Software (VAD) (Dentsply IH). They were made of either titanium (Figure 1), zirconia (Figure 2), or GoldHue (Figure 3). The system offers different options for a customized design of the abutments' emergence profile depending on the anatomic situation, as well as the possibility to compensate the position of implants with a prosthetically unfavorable placement through different angulations for the abutments. The basis for the milling process, performed by the manufacturer of the VAD software, was a 3D scan of a plaster cast with a silicone gingival mask (Picodent Dental) and a wax-up around the duplicate abutments in the respective implant regions. The clinician determined the abutment design by entering the instructions in a special virtual order form and sending the data to the manufacturer over the internet. 
Citation: Ketabi AR, Ketabi S, Brenner M, Lauer HC, Brandt S (2017) Retrospective Analysis of Biological and Technical Complications Using Individual CAD/CAM Abutments. Dentistry 7: 449. doi:10.4172/2161-1122.1000449

Page 3 of 9

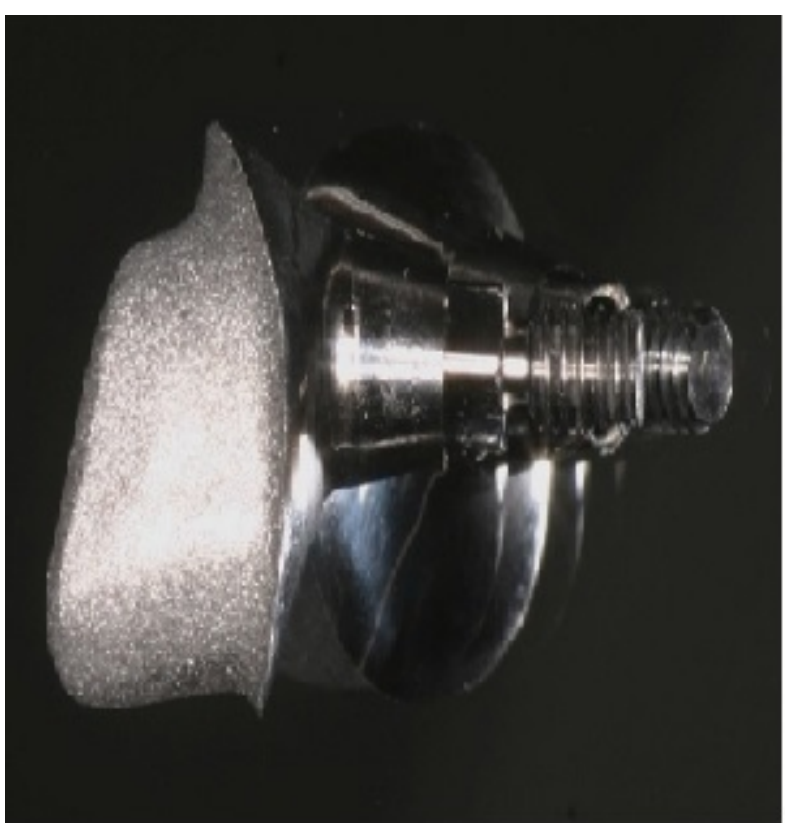

Figure 1: Atlantis abutment made of titanium.

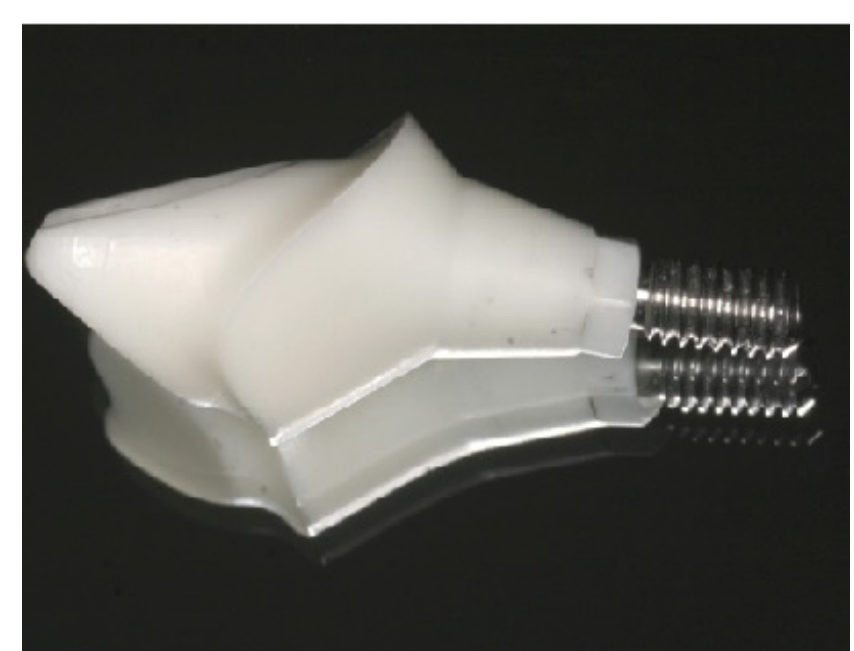

Figure 2: Atlantis abutment made of zirconia.

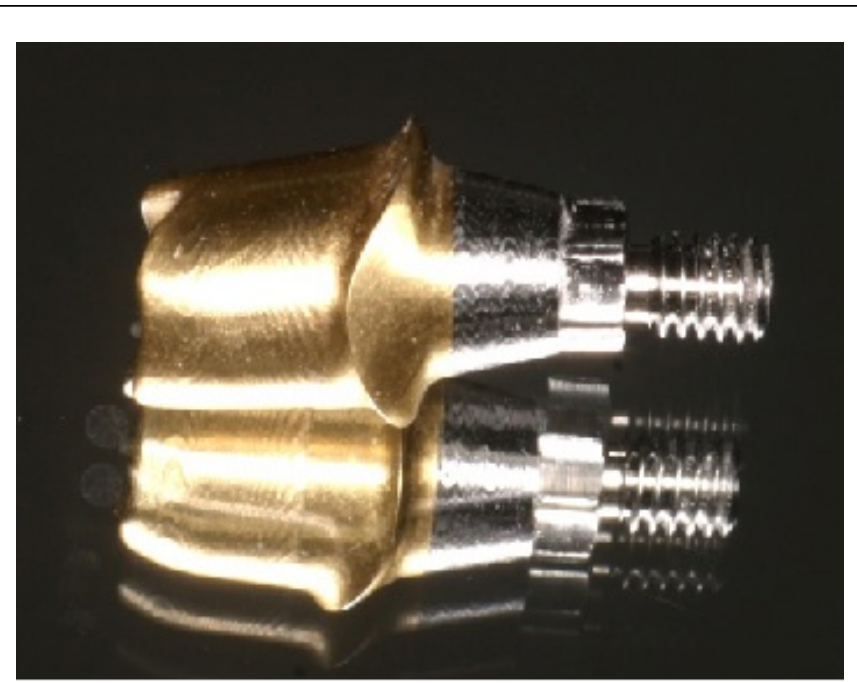

Figure 3: Atlantis abutment made of GoldHue.

The finished milled abutment was delivered to the practitioner with a corresponding abutment screw made of a titanium alloy. The definitive prosthetic restauration was fabricated by the dental technician. All abutments in the study were fabricated as described. The abutments were connected positioned with the help of a resin transfer key made by the technician and inserted at the torque recommended by the manufacturer. For the analysis of the materialspecific influence of the different abutments on clinical and radiological parameters, abutments made of GoldHue were assigned to the group of titanium abutments because of their identical material properties.

\section{Prosthetic superstructure}

The patients received cemented crowns and/or bridges made of veneered zirconia - Ceramill ZI (Amann Girrbach) or IPS e.max Press (IPS e.max, Ivoclar Vivadent) - or dentures retained by metalceramic and removable telescope crowns. All fixed superstructures were cemented with zinc oxide phosphate cement. The bridges were supported either by implants alone or by implants and natural teeth (hybrid bridges).

\section{Inclusion criteria}

The inclusion criteria for participation in the cohort study were as follows:

- At least one implant with an Atlantis abutment and a crown

- At least one follow-up examination one year after functional loading

- Documentation of clinical and radiologic parameters for a minimum of two years after delivery of the prosthetic superstructure

\section{Radiologic parameters}

Panoramic radiographs were obtained for pre-implantological diagnosis using the Orthophos D 3297 (Sirona Dental Systems). Conventional radiographs were taken at three different times using the parallel technique with a Sirona SR 60/70/7L tube. The first radiograph 
was taken immediately after implant placement in order to verify the insertion outcome. The second radiologic examination was performed at the time of delivering the final prosthetic restauration (baseline). The third radiograph was taken one year after functional loading of the implant (Figure 4).

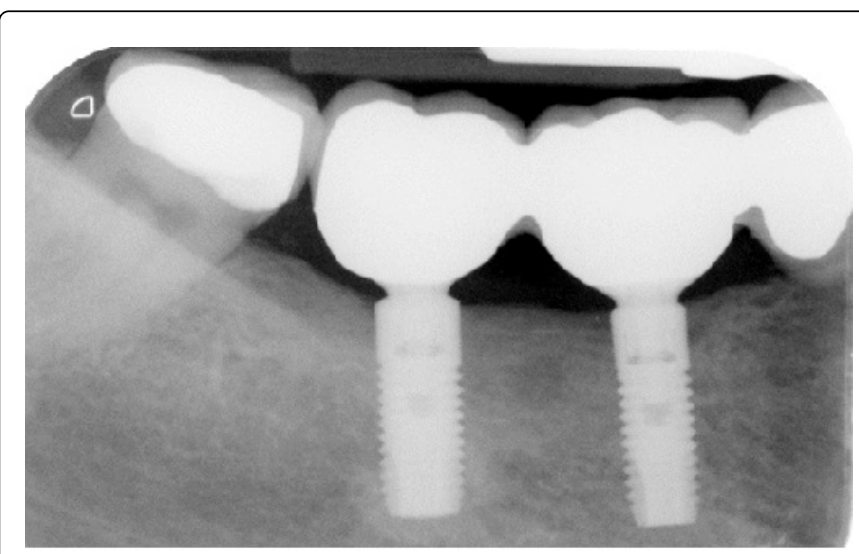

Figure 4: Conventional radiograph in parallel technique after one year of functional loading.

All radiographs were scanned with the VistaScan scanner $(\mathrm{S} / \mathrm{N}$ P000098; Dürr Dental) using the filtering functions of the original Dürr Dental software. The radiographs were edited (brightness adjustments, recalculation of image distortion, and magnification of image sections), and measurements were performed for final analysis.

\section{Method of measurement}

Because of its good radiological visibility, the implant shoulder was selected as the reference point for identifying changes in the crestal bone and measuring bone loss (Figure 5).

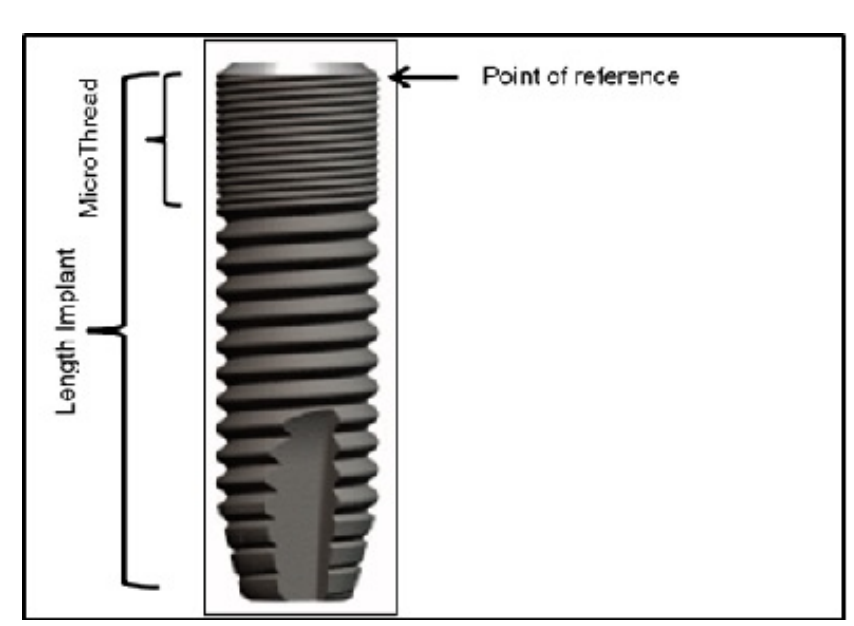

Figure 5: Implant reference points for the assessment of crestal-bone changes.

Two measurements were performed for each implant:

- Implant length, measured from the reference point to the apex of the implant or, alternatively, the length of the microthread (defined as the distance from the reference point to the end of the thread at the implant neck) if the implant was not displayed on the radiograph in its entirety.

- Bone levels on the mesial and distal side of the implant. This measurement was performed parallel to the implant axis from the point of reference to the first bone-to-implant contact (BIC). Any crestal bone loss or gain was reflect by negative or positive numbers, respectively. Radiographic distortion was detected and compensated for by the software, based on a comparison of known and measured implant dimensions.

The measurements were performed by a single examiner in a darkened room. To prevent the measuring accuracy from being affected by examiner fatigue, measurements were determined for a consecutive maximum of two hours. Each measurement was immediately documented in the data entry form; to avoid bias; it was repeated on a different day.

\section{Clinical parameters}

Soft-tissue conditions and the status of the prosthetic restauration were recorded at baseline and after one year in function. Soft-tissue quality was evaluated based on the mesial and distal height of the papilla and the color of the mucosa. Changes in papilla height were compared visually on photographs taken at baseline and at the followup. Changes in papillary soft-tissue levels were documented on an ordinal scale, with -1 denoting a height loss, 0 denoting no changes in papilla level, and 1 a height gain. Inflammation was assessed by a dichotomous variable $(\mathrm{no}=0$; yes $=1)$ for the composite parameter bleeding on probing, pain, and suppuration. Suppuration was detected by gentle pressure on the marginal peri-implant mucosa with a ballshaped dental instrument.

Prosthetic dentures were examined for any missing occlusal and approximal contacts or chipping of the ceramic veneer with and without exposure of the denture framework.

\section{Patient documentation form and questionnaire}

A self-developed form was used for documenting the respective clinical and radiological parameters. Another self-developed questionnaire was used to determine subjective patient-specific parameters regarding the treatment and esthetic considerations.

\section{Statistical methods}

All parameters were recorded with in Microsoft Excel (Microsoft Corporation) and the statistical analyses were performed with the Statistical Package for the Social Sciences (SPSS) Version 24 (International Business Machines). The level of significance was set to $\alpha=0.05$. Due to the small sample size, no significance testing could be performed, except regarding radiological changes in crestal bone levels as a function of the abutment material (Mann-Whitney $\mathrm{U}$ test).

\section{Result}

After a mean observation period of 20.85 (SD: 9.77) months, clinical and radiological data for 69 patients (49 female, 20 male) with 124 implants were available for analysis. Their mean age was 53.51 (29-78) years. Most of the abutments used in this study, were made from titanium ( $\mathrm{n}=87 ; 70.20 \%)$. Thirty-four abutments were fabricated of zirconia (27.40\%) and three were made of GoldHue (2.42\%) (Table 1). 


\begin{tabular}{|l|l|l|}
\hline Abutment material & Frequency & Percent \\
\hline Titanium & 87 & 70.16 \\
\hline Zirconia & 34 & 27.42 \\
\hline GoldHue & 3 & 2.42 \\
\hline Total & 124 & 100 \\
\hline
\end{tabular}

Prosthetic reconstructions made of zirconia were connected to 87 abutments $(70.16 \%)$ while metal-ceramic restorations were placed on 13 abutments (10.48\%). Materials other than zirconia or metalceramics (e.max or monolithic zirconia) were used on 24 abutments (19.36\%) (Table 2).

Table 1: Distribution of abutment material (124 abutments).

\begin{tabular}{|l|l|l|}
\hline $\begin{array}{l}\text { Material of prosthetic } \\
\text { superstructure }\end{array}$ & Frequency & Percent \\
\hline Zirconia & 87 & 70.16 \\
\hline Metal ceramics & 13 & 10.48 \\
\hline Others (e.max, monolithic zirconia) & 24 & 19.36 \\
\hline Total & 124 & 100 \\
\hline
\end{tabular}

Table 2: Distribution of the material of prosthetic superstructures.

Single implant-supported crowns were the most frequent prosthetic superstructures inserted in this study $(\mathrm{n}=88 ; 70.97 \%)$, followed by fixed partial bridges on 27 abutments (21.77\%). Hybrid bridges supported by implants and natural teeth were used on five abutments $(4.03 \%)$, and removable dentures were supported by four abutments by means of telescope crowns (3.23\%) (Table 3).

\begin{tabular}{|l|l|l|}
\hline Prosthetic superstructure & Frequency & Percent \\
\hline Single crowns & 88 & 70.97 \\
\hline Bridges (only implant-supported) & 27 & 21.77 \\
\hline Hybrid bridges (implant-ltooth-supported) & 5 & 4.03 \\
\hline Removable dentures & 4 & 3.23 \\
\hline Total & 124 & 100 \\
\hline
\end{tabular}

Table 3: Prosthetic superstructures.

Of the 27 abutments placed in the esthetic zone, 21 abutments were made of zirconia $(77.77 \%)$, while the other 6 were made of titanium (22.22\%).

\begin{tabular}{|c|c|c|c|c|c|}
\hline Bone level & Mean & SD & $\begin{array}{l}\text { Mean bone-level } \\
\text { change }\end{array}$ & SD & $p$ value \\
\hline Baseline mesial & 0.56 & 0.58 & \multirow[t]{2}{*}{0.06} & \multirow[t]{2}{*}{0.28} & \multirow[t]{2}{*}{0.550} \\
\hline One-year mesial & 0.62 & 0.62 & & & \\
\hline Baseline distal & 0.31 & 0.54 & \multirow[t]{2}{*}{0.11} & \multirow[t]{2}{*}{0.37} & \multirow[t]{2}{*}{0.050} \\
\hline One-year distal & 0.42 & 0.60 & & & \\
\hline
\end{tabular}

Table 4: Mean bone-level changes after one year (122 abutments).

\section{Crestal bone level changes}

Of the 124 implants/abutments, 122 were available for an analysis of the changes in mean crestal bone levels one year after implant insertion. Changes around 2 implants in 2 patients could not be
No implants or abutments were lost during the main observation period, resulting in a survival rate of $100.00 \%$ on the patient, implant, period, resulting in a analyzed due to measuring difficulties at the time of implant insertion. One of these 2 implants had received a titanium abutment, while the other one had received a zirconia abutment. The mean bone level at baseline on the mesial and distal sides of the implants was 0.56 and $0.31 \mathrm{~mm}$, respectively. At the second measurement, the mean bone 
level on the mesial and distal sides of the implants was 0.61 and 0.42 $\mathrm{mm}$, respectively, for an overall mean crestal bone gain of $0.06 \pm 0.28$ $\mathrm{mm}$ on the mesial sides and $0.11 \pm 0.37 \mathrm{~mm}$ on the distal sides of the 122 implants (Table 4).

A statistical significant influence of the abutment material on crestal bone levels could not be radiologically assessed either on the mesial $(\mathrm{p}=0.550)$ or on the distal side $(\mathrm{p} \geq 0.05)$ of the implants (MannWhitney U test).

\section{Biological complications}

Changes in papilla height were recorded as an ordinal variable ($1=$ loss; $0=$ no change; $+1=$ gain of papilla height). Gain in papilla height on the mesial and distal side as well could be observed after the observation period in the most cases at the abutment level $(n=117)$ and at the patient level $(n=65)$. Five abutments in four patients showed no changes in papilla height. Two abutments in one patient (sites 15 and 16) revealed a loss of papilla height. Bleeding on probing (BOP) was recorded on the distal and mesial side of both implants (1.45\%). Crestal bone loss occurred here on the distal side of implant $15(1.00$ $\mathrm{mm})$, and on both the mesial $(1.50 \mathrm{~mm})$ and distal aspects $(1.00 \mathrm{~mm})$ of implant 16, whereas no bone loss was found on the mesial side of implant 15 . Another soft-tissue complication, namely reddening of the mucosa around a zirconia abutment, was observed in another patient in the esthetic zone of the maxilla (site 22) but without any clinical/ radiological consequences for the hard and soft tissues (1.45\%).

\section{Technical complications}

None of the technical complications were associated with biological complications or crestal bone loss. No abutment fractures and no loosening or fractures of abutment screws were seen. Other technical complications in terms of veneer fractures were observed in two patients. In one patient, the veneer of four implant-supported zirconia single crowns in the left posterior maxilla exhibited chipping. Three crowns $(24,25$, and 26$)$ were involved but without framework exposure $(2.46 \%)$, whereas the veneering material of the implant-supported crown 27 fractured and exposed the framework. In the second patient there was also a fracture with framework exposure in the posterior maxilla at implant 27 . The total fracture rate with framework exposure was $1.64 \%$. Five restorations in four patients showed insufficient occlusal contacts $(4.00 \%)$. One restoration revealed an insufficient proximal contact situation on the mesial side $(0.80 \%)$, and a proximal contact in another patient was too tight $(0.80 \%)$.

In total, eight restorations had to be replaced in five patients. Four restorations were replaced in the patient exhibiting fractures with and without framework exposure. The fractured restoration in the second patient, with framework exposure, remained in place at the patient's request. The two restorations in the patient with biological complications at sites 15 and 16 were also replaced. An additional two restorations were replaced in a patient who was dissatisfied with the therapeutic and esthetic result.

Based on these findings, the cumulative prosthetic survival rate at the abutment and implant levels was of $93.50 \%$. At the patient level, the cumulative survival rate of the superstructures was $92.75 \%$. The implant and abutment survival rate was $100.00 \%$.

\section{Patient satisfaction}

The majority of patients showed a very high degree of satisfaction with the therapy in principle and with the aesthetic result of the prosthetic superstructure after one year in function. The treatment was rated as very good by $63(92.65 \%)$ and as food by $4(5.88 \%)$ patients out of 68 . The esthetic result rate as was estimated as very good 61 $(88.41 \%)$ and as good by $7(10.14 \%)$ patients out of 69 . Only one patient was disaffected with the therapeutic $(1.47 \%)$ and the esthetic result $(1.45 \%)$, although neither biological nor technical complications were present in this patient (Table 5).

\begin{tabular}{|l|l|l|l|l|}
\hline \multicolumn{3}{|c|}{ Esthetics } & Therapy \\
\hline Rating & Frequency & Percent & Frequency & Percent \\
\hline Very good & 61 & 88.41 & 63 & 92.64 \\
\hline Good & 7 & 10.14 & 4 & 5.88 \\
\hline Pleasible & 0 & 0 & 0 & 0 \\
\hline Acceptable & 0 & 0 & 0 & 0 \\
\hline Poor & 1 & 1.45 & 1 & 1.47 \\
\hline Total & 69 & 100 & 68 & 100 \\
\hline
\end{tabular}

Table 5: Results of the patient questionnaire, $n=69$ patients (one patient did not rate his satisfaction with the therapeutic result).

The same patient had received two abutments and crowns made of zirconia in the esthetic maxillary esthetic zone (sites 21 and 23). Both crowns were replaced due to his displeasure with the therapeutic and esthetic result. However, the patient who had experience three veneer fractures without and one veneer fracture with framework exposure rated the esthetic and therapeutic result as very good. The patient with the exposed framework after fracture of the superstructure also rated esthetics and therapy as very good.

\section{Discussion}

The impact of the material properties of zirconia and titanium on the therapeutic and esthetic results in implant prosthetics has been the subject of many recent papers. With respect to esthetics, evidence of a material-related influence is still uncertain. Both materials exhibited significant shade differences in the peri-implant soft tissue compared to adjacent natural teeth in a randomized controlled clinical trial (RCT) [13]. Significant shade differences between titanium and zirconia abutments were found within $1.00 \mathrm{~mm}$ of the gingival margin prior to crown cementation in the same study. Differences between the two materials were still present after cementation, but these differences were not statistically significant. A different publication, by contrast, reported significantly lower shade differences with zirconia abutments compared to titanium and GoldHue abutments [54]. A systematic review confirmed a significant trend toward better esthetic outcomes around zirconia abutments [12], while the results of another systematic review revealed no esthetic differences between zirconia and titanium abutments [55].

In the present study, the majority of patients were highly satisfied with the esthetic treatment outcome. Due to the very small number of GoldHue abutments and the still relatively small number of zirconia abutments compared to the many titanium abutments, no test for 
statistical significance concerning satisfaction with the esthetic result as a function of the abutment material could be performed. Given the high level of patient acceptance, even though most abutments in the present study were made of titanium, the abutment material might be negligible as a factor influencing patients' perception of esthetics.

Based on the results of a recent clinical study, patients tend to be more satisfied with the esthetic result in terms of restoration shade than the clinician [54]. As the assessment was made using a five-point scale that reflected the patients' subjective opinions rather than being supported by objective parameters such as colorimeter [13] or spectrophotometry readings [55], the reliability of the questionnaire results might questioned. Assessments of a recent RCT published by Ferrari et al. revealed a low incidence of soft-tissue complications and no significant differences between titanium, GoldHue, and zirconia with respect to complications in the peri-implant tissue, such as midfacial recession in partially edentulous patients, irrespective of the patients' gingival phenotypes [56].

Although no statistical analysis of the material's influence on softtissue parameters and biological complications was possible in the cohort study, we observed a very low incidence of soft-tissue complications, confirming the results of the study by Ferrari et al. Softtissue complications were recorded only in a few cases, manifesting as redness of the peri-implant mucosa in one case and as bleeding on probing and a loss of papilla height in another patient. Crestal bone loss was observed in conjunction with the loss of papilla height in the same patient. No significant influence of the material on the soft or hard tissue was observed. This finding agrees with the results of a systematic review by Linkevičius and Apse that revealed no influence of the abutment material on hard-tissue levels [17].

Bone levels increased in the present study through the follow-up. This finding is not supported by current scientific evidence, which in principle suggests bone remodeling takng place in connection with implant placement, resulting in crestal bone loss after the first postsurgical year [57-59]. Neither implant loss nor implant-related complications were observed, resulting in a survival rate of $100.00 \%$ for implants and abutments and a complication rate of $0 \%$ after one year in function, which is better than or equal to the results reported elsewhere [60,61].

The incidence of technical complications such as veneer fractures was also very low. The fracture rate seemed to depend on the specific patient situation, because four of the five fractures occurred in one and the same patient. In total, eight restorations had to be replaced due to technical or esthetic problems, for a cumulative prosthetic survival rate of $93.50 \%$ on the implant and abutment levels. The high survival rate in the present study is comparable with the results in other publications $[44,43,62]$.

\section{Conclusions}

Because only custom CAD/CAM abutments were used in the present cohort study, no comparison to stock abutments was performed, which somewhat limits the information value of our results and does not allow the postulation of additional CAD/CAM-related benefits in terms of functional and esthetical outcomes.

Yet despite these limitations, the low complication rates in the present study and the high level of patient satisfaction with implantsupported prosthetic superstructures supported by CAD/CAM abutments after one year in function is very promising and would support the treatment concept and protocol presented.

\section{References}

1. Romanos GE (2015) Tissue preservation strategies for fostering long-term soft and hard tissue stability. Int J Periodontics Restorative Dent 35: 363-371.

2. Zhao X, Qiao SC, Shi JY, Uemura N, Arai K, Lai HC (2016) Evaluation of the clinical and aesthetic outcomes of Straumann((R)) Standard Plus implants supported single crowns placed in non-augmented healed sites in the anterior maxilla: a 5-8 years retrospective study. Clin oral implants Res 27:106-112.

3. Kois JC, Kan JY (2001) Predictable peri-implant gingival aesthetics: surgical and prosthodontic rationales. Pract Proced Aesthet Dent 13: 691-698.

4. Wenzel BA, Gamborena I, Lee J, Fiorini T, Schupbach P, et al. (2014) Effect of Platform Shift on Crestal Bone Levels and Mucosal Profile Following Flap Surgery and Subcrestal Implant Placement in Presence/ Absence of Gap Defects. Clin implant dent relat Res 18: 217-225.

5. Bashutski JD, Wang HL, Rudek I, Moreno I, Koticha T, et al. (2013) Effect of flapless surgery on single-tooth implants in the esthetic zone: a randomized clinical trial. J periodontol 84:1747-1754.

6. Vohra F, Al-Kheraif AA, Almas K, Javed F (2015) Comparison of crestal bone loss around dental implants placed in healed sites using flapped and flapless techniques: a systematic review. J periodontol 86:185-191.

7. Schwarz F, Hegewald A, Becker J (2014) Impact of implant-abutment connection and positioning of the machined collar/microgap on crestal bone level changes: a systematic review. Clin oral implants Res 25:417-425.

8. Fickl S, Zuhr O, Stein JM, Hurzeler MB (2010) Peri-implant bone level around implants with platform-switched abutments. Int J Oral Maxillofac Implants 25:577-581.

9. Wenzel BA, Gamborena I, Lee J, Fiorini T, Schupbach P, et al. (2016) Effect of Platform Shift on Crestal Bone Levels and Mucosal Profile Following Flap Surgery and Subcrestal Implant Placement in Presence/ Absence of Gap Defects. Clin implant dent relat Res 18:217-225.

10. Al-Nsour MM, Chan HL, Wang HL (2012) Effect of the platformswitching technique on preservation of peri-implant marginal bone: a systematic review. The Int J Oral Maxillofac Implants 27: 138-145.

11. Raisanen L, Kononen M, Juhanoja J, Varpavaara P, Hautaniemi J, et al. (2000) Expression of cell adhesion complexes in epithelial cells seeded on biomaterial surfaces. J Biomed Mater Res 49: 79-87.

12. Linkevicius T, Vaitelis $J$ (2015) The effect of zirconia or titanium as abutment material on soft peri-implant tissues: a systematic review and meta-analysis. Clin Oral Implants Res 26: 139-147.

13. Cosgarea R, Gasparik C, Dudea D, Culic B, Dannewitz B, et al. (2015) Peri-implant soft tissue colour around titanium and zirconia abutments: a prospective randomized controlled clinical study. Clin oral implants Res 26: $537-544$.

14. Berglundh T, Lindhe J, Ericsson I, Marinello CP, Liljenberg B, et al. (1991) The soft tissue barrier at implants and teeth. Clin oral implants Res 2: 81-90.

15. Okabe E, Ishihara Y, Kikuchi T, Izawa A, Kobayashi S, et al. (2015) Adhesion Properties of Human Oral Epithelial-Derived Cells to Zirconia. Clin implant dent relat Res 18: 906-916.

16. Liu C, Su Y, Tan B, Ma P, Wu G, et al. (2014) Reconstruction of attached soft tissue around dental implants by acelluar dermal matrix grafts and resin splint. Int J Clin Exp Med 7: 4666-4676.

17. Linkevicius T, Apse P (2008) Influence of abutment material on stability of peri-implant tissues: a systematic review. Int J Oral Maxillofac Implants 23: $449-456$.

18. Annibali S, Bignozzi I, Cristalli MP, Graziani F, La Monaca G, et al. (2012) Peri-implant marginal bone level: a systematic review and meta-analysis 
of studies comparing platform switching versus conventionally restored implants. J clin periodontol 39: 1097-1113.

19. Telleman G, Meijer HJ, Vissink A, Raghoebar GM (2013) Short implants with a nanometer-sized $\mathrm{CaP}$ surface provided with either a platformswitched or platform-matched abutment connection in the posterior region: a randomized clinical trial. Clin oral implants Res 24:1316-1324.

20. Telleman G, Raghoebar GM, Vissink A, Meijer HJ (2012) Impact of platform switching on inter-proximal bone levels around short implants in the posterior region; 1-year results from a randomized clinical trial. J clin periodontol 39: 688-697.

21. Trammell K, Geurs NC, O'Neal SJ, Liu PR, Haigh SJ, et al. (2009) A prospective, randomized, controlled comparison of platform-switched and matched-abutment implants in short-span partial denture situations. Int J Periodontics Restorative Dent 29: 599-605.

22. Vandeweghe S, De Bruyn H (2012) A within-implant comparison to evaluate the concept of platform switching: a randomised controlled trial. Eur J Oral Implantol 5: 253-262.

23. Gamborena I, Lee J, Fiorini T, Wenzel BA, Schupbach P, et al. (2015) Effect of Platform Shift/Switch and Concave Abutments on Crestal Bone Levels and Mucosal Profile following Flap and Flapless Implant Surgery. Clin Implant Dent Relat Res 17: 908-916.

24. Lee J, Fiorini T, Gamborena I, Wenzel BA, Schupbach P, et al. (2016) Effect of Platform Shift/Switch on Crestal Bone Levels and Mucosal Profile Following Flapless Surgery and Crestal/Subcrestal Implant Placement. Clin implant Dent Relat Res 18: 73-81.

25. Martin WC, Pollini A, Morton D (2014) The influence of restorative procedures on esthetic outcomes in implant dentistry: a systematic review. Int J Oral Maxillofac Implants 29: 142-154.

26. Joda T, Ferrari M, Braegger U (2016) A digital approach for one-step formation of the supra-implant emergence profile with an individualized CAD/CAM healing abutment. J Prosthodont Res 60: 220-223.

27. Monaco C, Evangelisti E, Scotti R, Mignani G, Zucchelli G (2015) A fully digital approach to replicate peri-implant soft tissue contours and emergence profile in the esthetic zone. Clin Oral Implants Res 27: 1511-1514.

28. Spyropoulou PE, Razzoog M, Sierraalta M (2009) Restoring implants in the esthetic zone after sculpting and capturing the periimplant tissues in rest position: a clinical report. J Prosthet Dent 102: 345-347.

29. Al-Harbi SA, Edgin WA (2007) Preservation of soft tissue contours with immediate screw-retained provisional implant crown. J Prosthet Dent 98: 329-332.

30. Ntounis A, Petropoulou A (2010) A technique for managing and accurate registration of periimplant soft tissues. J Prosthet Dent 104: 276-279.

31. Ganz SD (2003) Computer-milled patient-specific abutments: incredibly quality with unprecedented simplicity. Implantology 2003: 37-44.

32. Ganz SD (2003) Use of stereolithographic models as diagnostic and restorative aids for predictable immediate loading of implants. Pract Proced Aesthet Dent 15: 763-771.

33. Ganz SD (2005) Finally, a 'win-win' solution: Increasing accuracy while saving time, money with computermilled abutments Dental Economics.

34. Ganz SD (2007) CT-derived model-based surgery for immediate loading of maxillary anterior implants. Pract Proced Aesthet Dent 19: 311-318.

35. Ganz SD (2008) Defining new paradigms for assessment of implant receptor sites. The use of $\mathrm{CT} / \mathrm{CBCT}$ and interactive virtual treatment planning for congenitally missing lateral incisors. Compend Contin Educ Dent 29: 256-258, 260-252, 264-257.

36. Schneider A, Kurtzman GM (2001) Computerized milled solid implant abutments utilized at second stage surgery. Gen Dent 49: 416-420.

37. Watkin A, Kerstein RB (2008) Improving darkened anterior peri-implant tissue color with zirconia custom implant abutments. Compend Contin Educ Dent 29: 238-240, 242.

38. Priest G (2005) Virtual-designed and computer-milled implant abutments. Journal of oral and maxillofacial surgery. Journal Oral and Maxillofacial Surgery 63: 22-32.
39. Apicella D, Veltri M, Chieffi N, Polimeni A, Giovannetti A, et al. (2010) Implant adaptation of stock abutments versus CAD/CAM abutments: a radiographic and Scanning Electron Microscopy study. Ann Stomatol (Roma) 1: 9-13.

40. Garg AK (2002) The Atlantis Components Abutment: simplifying the tooth implant procedure. Dent implantol update 13: 65-70.

41. Adams MW (2005) Computer-designed and milled patient-specific implant abutments. Dent today 24: 80-83.

42. Osorio J (2000) Use of the Atlantis Abutment in restorative practice speeds time to function and aesthetics. Dent implantolo update 11: 57-62.

43. Muddugangadhar BC, Amarnath GS, Sonika R, Chheda PS, Garg A (2015) Meta-analysis of Failure and Survival Rate of Implant-supported Single Crowns, Fixed Partial Denture, and Implant Tooth-supported Prostheses. J Int Oral Health 7: 11-17.

44. Jung RE, Zembic A, Pjetursson BE, Zwahlen M, Thoma DS (2012) Systematic review of the survival rate and the incidence of biological, technical, and aesthetic complications of single crowns on implants reported in longitudinal studies with a mean follow-up of 5 years. Clin oral implants Res 23: 2-21.

45. Wittneben JG, Millen C, Bragger U (2014) Clinical performance of screwversus cement-retained fixed implant-supported reconstructions-a systematic review. Int J Oral Maxillofac Implants 29: 84-98.

46. Sailer I, Muhlemann S, Zwahlen M, Hammerle CH, Schneider D (2012) Cemented and screw-retained implant reconstructions: a systematic review of the survival and complication rates. Clin oral implants Res 23: 163-201.

47. Millen C, Bragger U, Wittneben JG (2015) Influence of prosthesis type and retention mechanism on complications with fixed implant-supported prostheses: a systematic review applying multivariate analyses. Int J Oral Maxillofac Implants 30: 110-124.

48. Ma S, Fenton A (2015) Screw- versus cement-retained implant prostheses: a systematic review of prosthodontic maintenance and complications. Int J prosthodont 28: 127-145.

49. Pjetursson BE, Bragger U, Lang NP, Zwahlen M (2007) Comparison of survival and complication rates of tooth-supported fixed dental prostheses (FDPs) and implant-supported FDPs and single crowns (SCs). Clin oral implants Res18: 97-113.

50. Lang NP, Pjetursson BE, Tan K, Bragger U, Egger M, et al. (2004) A systematic review of the survival and complication rates of fixed partial dentures (FPDs) after an observation period of at least 5 years. II. Combined tooth--implant-supported FPDs. Clin oral implants Res 15: 643-653.

51. Nickenig HJ, Schafer C, Spiekermann H (2006) Survival and complication rates of combined tooth-implant-supported fixed partial dentures. Clin oral implants Res 17: 506-511.

52. do Amaral GS, de Cássia Negrini T, Maltz M, Arthur RA (2016) Restorative materials containing antimicrobial agents: is there evidence for their antimicrobial and anticaries effects? A systematic review. Aust Dent J 61: 6-15.

53. Chen ST, Buser D (2009) Clinical and esthetic outcomes of implants placed in postextraction sites. Int J Oral Maxillofac Implants 24: 186-217.

54. Kim A, Campbell SD, Viana MA, Knoernschild KL (2015) Abutment Material Effect on Peri-implant Soft Tissue Color and Perceived Esthetics. J Prosthodont 25: 634-640.

55. Zembic A, Sailer I, Jung RE, Hammerle CH (2009) Randomizedcontrolled clinical trial of customized zirconia and titanium implant abutments for single-tooth implants in canine and posterior regions: 3year results. Clin oral implants Res 20: 802-808.

56. Ferrari M, Cagidiaco MC, Garcia-Godoy F, Goracci C, Cairo F (2015) Effect of different prosthetic abutments on peri-implant soft tissue. A randomized controlled clinical trial. Am J Dent 28: 85-89.

57. O'Neill JE, Yeung SC (2011) Do dental implants preserve and maintain alveolar bone. J Investig Clin Dent 2: 229-235.

58. van Eekeren PJ, Tahmaseb A, Wismeijer D (2016) Crestal Bone Changes Around Implants with Implant-Abutment Connections at Epicrestal 
Citation: Ketabi AR, Ketabi S, Brenner M, Lauer HC, Brandt S (2017) Retrospective Analysis of Biological and Technical Complications Using Individual CAD/CAM Abutments. Dentistry 7: 449. doi:10.4172/2161-1122.1000449

Page 9 of 9

Level or Above: Systematic Review and Meta-Analysis. Int J Oral Maxillofac Implants 31: 119-124.

59. Moraschini V, Velloso G, Luz D, Porto Barboza E (2015) Implant survival rates, marginal bone level changes, and complications in full-mouth rehabilitation with flapless computer-guided surgery: a systematic review and meta-analysis. Int J Oral Maxillofac Implants 44: 892-901.

60. Thoma DS, Brandenberg F, Fehmer V, Buchi DL, Hammerle CH, et al. (2016) Randomized Controlled Clinical Trial of All-Ceramic Single Tooth Implant Reconstructions Using Modified Zirconia Abutments: Radiographic and Prosthetic Results at 1 Year of Loading. Clin Implant Dent Relat Res 18: 462-472.
61. Brandenberg FD, Sailer I, Fehmer V, Buchi DL, Hammerle CH, Thoma DS (2016) Randomized controlled clinical pilot study of all-ceramic single-tooth implant reconstructions: clinical and microbiological outcomes at one year of loading. Clin Oral Implants Res 28: 406-413.

62. Sailer I, Pjetursson BE, Zwahlen M, Hammerle CH (2007) A systematic review of the survival and complication rates of all-ceramic and metalceramic reconstructions after an observation period of at least 3 years. Part II: Fixed dental prostheses. Clin oral implants Res 18: 86-96. 